\title{
Synthesis and Antiplatelet Adhesion Behavior of a Poly(L-lactide-co- glycolide)-Poly(1,5-dioxepan-2-one) Multiblock Copolymer
}

\author{
Mitsutoshi Jikei,* Mao Takeda, Yoshiki Kaneda, Kohei Kudo, Nozomi Tanaka, Kazuya Matsumoto, \\ Masaki Hikida, and Shigeharu Ueki
}

Cite This: ACS Omega 2021, 6, 27968-27975

Read Online

ACCESS

山ll Metrics \& More

Article Recommendations

Supporting Information

ABSTRACT: Platelet adhesion and denaturation on artificial medical implants induce thrombus formation. In this study, bioabsorbable copolymers composed of poly(L-lactide-co-glycolide) (PLGA) and poly(1,5-dioxepan-2-one) (PDXO) were synthesized and evaluated for their antiplatelet adhesive properties. The PLGA-PXO multiblock copolymer (PLGA-PDXO MBC) and its random copolymer (PLGA-PDXO RC) showed effective antiplatelet adhesive properties, and the number of adhered platelets was similar to those adhered on poly(2-methoxyethylacrylate), a known antiplatelet adhesive polymer, although a large number of denatured platelets were observed on a PLGA-poly $(\varepsilon$ -

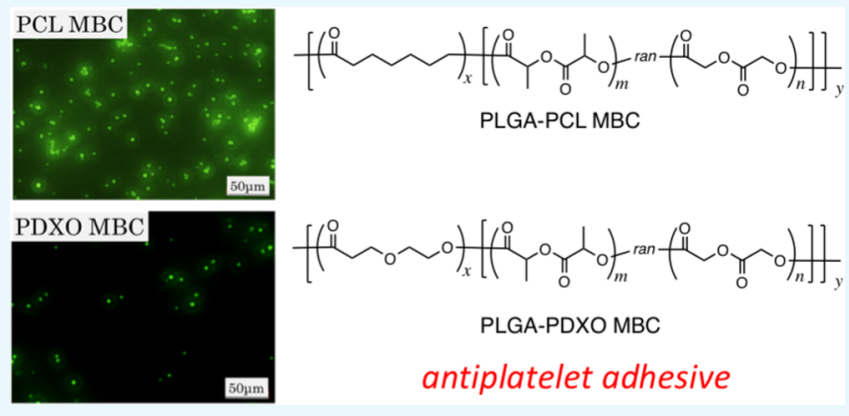
caprolactone) multiblock copolymer (PLGA-PCL MBC). Using monoclonal antifibrinogen IgG antibodies, we also found that both $\alpha \mathrm{C}$ and $\gamma$-chains, the binding sites of fibrinogen for platelets, were less exposed on the PLGA-PDXO MBC surface compared to PLGA-PCL MBC. Furthermore, free-standing films of PLGAPDXO MBC were prepared by casting the polymer solution on glass plates and showed good tensile properties and slow hydrolytic degradation in phosphate-buffered saline $(\mathrm{pH}=7.4)$. We expect that the unique properties of PLGA-PDXO MBC, i.e., antiplatelet adhesive behavior, good tensile strength, and hydrolytic degradation, will pave the way for the development of new bioabsorbable implanting materials suitable for application at blood-contacting sites.

\section{INTRODUCTION}

Bioabsorbable polymers, such as poly(L-lactide) (PLLA), are promising implanting materials, which can be metabolized after disease recovery. ${ }^{1-7}$ Especially, bioabsorbable sutures composed of PLLA and poly(glycolide) copolymers are extensively used, while bioabsorbable bone screws and bone plates have been widely applied in the orthopedic field. PLLA is a hard plastic with a glass transition $\left(T_{\mathrm{g}}\right)$ of $60{ }^{\circ} \mathrm{C}$ and a melting temperature of $180{ }^{\circ} \mathrm{C}$. However, implanting materials should be soft and elastic when they come in contact with soft tissues. Therefore, PLLA is commonly copolymerized and/or blended with low- $T_{\mathrm{g}}$ materials to prepare PLLA-based materials with elastic properties. ${ }^{8,9}$ Poly $(\varepsilon$-caprolactone) (PCL) is often used as a biodegradable soft component. We have also previously prepared and characterized segmented multiblock copolymers (MBCs) of PLLA or poly(L-lactide-co-glycolide) (PLGA) and PCL, which showed improved tensile properties compared to their corresponding random copolymers due to the microphase-separated morphology of PLLA or PLGA and PCL. ${ }^{10-13}$

When the materials composed of synthetic polymers are implanted and come in contact with blood, their surface is immediately covered by plasma proteins, affecting their adhesion to cells. Since platelet adhesion and aggregation on the polymer surface induce the thrombus formation, antiplatelet adhesive surfaces are needed to develop antithrombogenic materials. Several studies have reported that microphase-separated morphology can effectively suppress the platelet adhesion. ${ }^{14-21}$ Hydrophilic-hydrophobic and amorphous-crystalline-type microphase-separated block copolymers have been developed and examined as antiplatelet adhesive polymers. Ishihara et al. reported that poly(2methacryloyloxyethyl phosphorylcholine)-co- $n$-butyl methacrylate showed good hemocompatibility, as the phosphorylcholine group is one of the red blood cell membrane proteins and could effectively suppress platelet adhesion..$^{22-26}$ In addition to antiplatelet adhesion, the highly hydrophilic surface of the 2methacryloyloxyethyl phosphorylcholine copolymer (PMPC) was exploited for the development of contact lenses and artificial hip joints. ${ }^{27}$ Tanaka et al. reported that poly(2methoxyethylacrylate) (PMEA) has also shown antiplatelet adhesive properties and pointed out that the intermediate

Received: July 20, 2021

Accepted: September 30, 2021

Published: October 13, 2021 
Scheme 1. Synthesis of PLGA-PDXO MBC

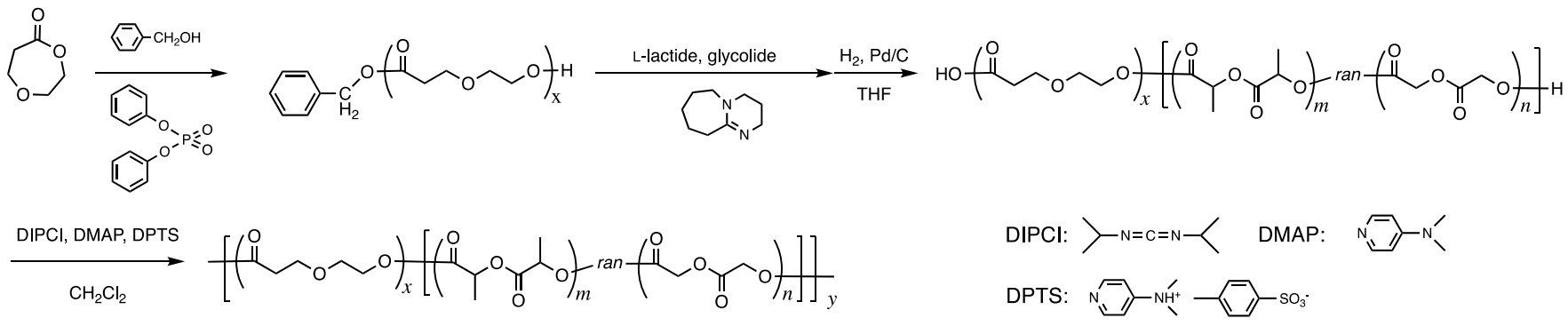

water, which loosely interacts with the surface polymer, plays a crucial role in antiplatelet adhesive behavior. ${ }^{28-30}$ Cellselective adhesion and cell culture on the PMEA surface have also been reported. ${ }^{31-33}$ However, both PMPC and PMEA are not bioabsorbable. It is recently reported that the polycarbonate copolymers bearing a 2-methoxyethoxy carbonyl group showed antithrombogenicity, vascular cell adhesion, and enzymatic degradation. ${ }^{34}$

To further expand the range of bioabsorbable polymeric materials, we synthesized and examined the antiplatelet adhesive effect of copolymers consisting of PLGA and poly(1,5-dioxepan-2-one) (PDXO). PDXO is reported as a hydrophilic polymer, ${ }^{35-38}$ but the interaction with blood components has not been reported in the literature. We found that PLGA-PDXO MBC and its random copolymer showed antiplatelet adhesion behavior. The adhesion behavior of fibrinogen on the surface was investigated to discuss the relationship between the protein adsorption/orientation and the antiplatelet adhesive behavior. Moreover, free-standing films of PLGA-PDXO MBC were easily prepared due to its improved mechanical properties compared to other known antiplatelet adhesive polymers. The biodegradability of PLGA-PDXO MBC was further confirmed by a hydrolysis test in phosphate-buffered saline (PBS).

\section{RESULTS AND DISCUSSION}

Synthesis and Characterization of PLGA-PDXO MBC. PLGA-PDXO MBC was synthesized by the self-polycondensation of the PLGA-PDXO diblock copolymer (Scheme 1). The degree of polymerization of DXO and L-lactide + glycolide was set to 25 by adjusting the feed ratio of the initiator and the monomers. ${ }^{1} \mathrm{H}$ NMR measurements gave the information about the ratio of components and the degree of polymerization in the diblock copolymer (Figures S1 and S2). The peaks in Figure 1 were assigned to the corresponding structure of PLGA-PDXO MBC. PLGA-PCL MBC was prepared following the same process based on a previous study. ${ }^{11}$

Given that the PDXO homopolymer is hydrophilic and the incorporation of $\mathrm{PDXO}$ segments increases the copolymer hydrophilicity, ${ }^{38}$ contact angle measurements were performed to evaluate the hydrophilicity of PLGA-PDXO MBC and PLGA-PCL MBC. The contact angle of a water droplet on PLGA-PDXO MBC $\left(77.0 \pm 0.9^{\circ}\right)$ was slightly smaller $(P<$ $0.01)$ than that on PLGA-PCL MBC $\left(78.5 \pm 1.4^{\circ}\right)$. However, after $10 \mathrm{~min}$, the contact angle of PLGA-PDXO MBC was reduced to $59.0 \pm 3.9^{\circ}$, while that of PLGA-PCL MBC was reduced to $65.1 \pm 4.6^{\circ}$, indicating that the hydrophilicity of PLGA-PDXO MBC was slightly higher than that of PLGAPCL MBC.

Platelet Adhesion. To investigate the adhesion of platelets on the prepared copolymers (Figure 2), a platelet suspension

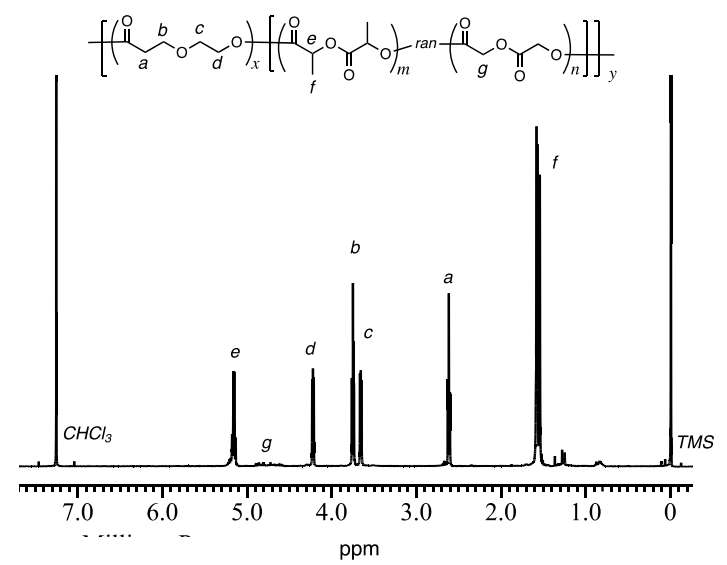

Figure 1. ${ }^{1} \mathrm{H}$ NMR spectrum of PLGA-PDXO $\mathrm{MBC}$ in $\mathrm{CDCl}_{3}$.

was placed on each polymer-coated glass plate and incubated at $37{ }^{\circ} \mathrm{C}$ for $1 \mathrm{~h}$. The number of platelets adhered on the polymer-coated glass plates was then estimated by staining their cytoskeletons (F-actins) with ActinGreen. Based on the number of green spots (Figure 3), significantly less platelets were adhered on the PDXO-containing copolymer surfaces compared to those on the PLGA-PCL MBC surface. Moreover, the number of platelets on the PDXO copolymer surface was similar to that on the PMEA surface, which was used as a positive control, ${ }^{28,30}$ suggesting that PDXOcontaining copolymers have an antiplatelet adhesion effect. A noticeable difference in the number of adhered platelets between PLGA-PDXO MBC and PLGA-PDXO RC was not observed, although microphase-separated morphology was observed in the AFM phase image (Figure S3) of PLGAPDXO MBC. Therefore, microphase-separated morphology did not play a crucial role to show antiplatelet adhesion behavior. Figure 4 shows typical examples of the scanning electron microscopy (SEM) images of adhered platelets on PLGA-PDXO MBC and PLGA-PCL MBC. The platelets adhered on PLGA-PDXO MBC kept their original round shape. On the other hand, the platelets adhered on PLGAPCL MBC had spread, suggesting the activation of platelets on the surface. In contrast to the copolymers, no significant difference was observed between the surfaces coated with PLGA-PCL MBC and the PDXO homopolymer (Figure 5), indicating that the PDXO homopolymer does not show antiplatelet adhesion behavior. Although the difference between PDXO-containing copolymers and the PDXO homopolymer could not be fully understood, we assume that a large PDXO domain in the homopolymer, which does not exist in PDXO-containing copolymers, may favor the adhesion of platelets. In addition, the amount of the PDXO component 


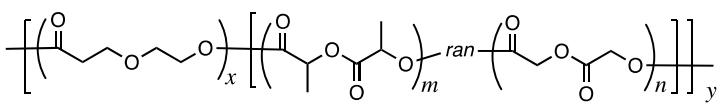

PLGA-PDXO MBC

$M_{\mathrm{w}}=119,000, M_{\mathrm{w}} / M_{\mathrm{n}}=1.59, x=26,(m+n)=27$

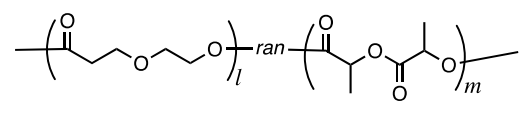

PLLA-PDXO RC

$M_{\mathrm{w}}=43,000, M_{\mathrm{w}} / M_{\mathrm{n}}=1.98, I: m=0.9: 1.0$

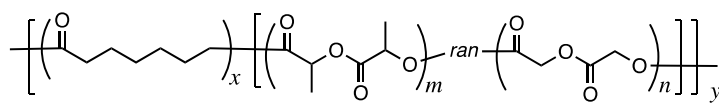

PLGA-PCL MBC

$M_{\mathrm{w}}=142,000 M_{\mathrm{w}} / M_{\mathrm{n}}=2.30, x=23,(m+n)=23$<smiles>CC(C)(C)OCCOCCC(C)(C)C(C)(C)O</smiles>

PDXO Homo

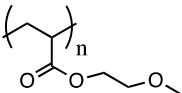

PMEA

Figure 2. List of polymers examined for platelet adhesion experiments.

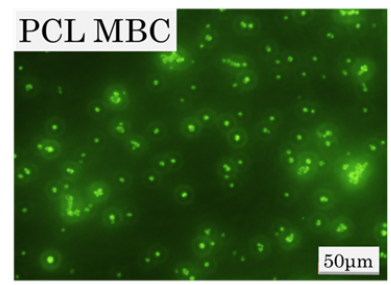

PDXO MBC

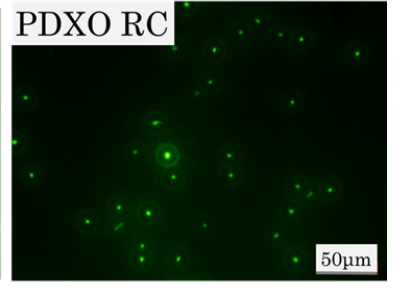

PMEA

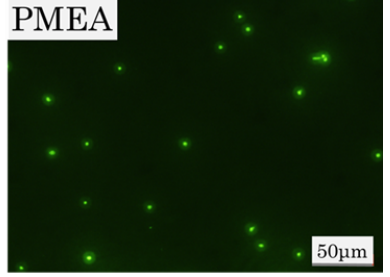

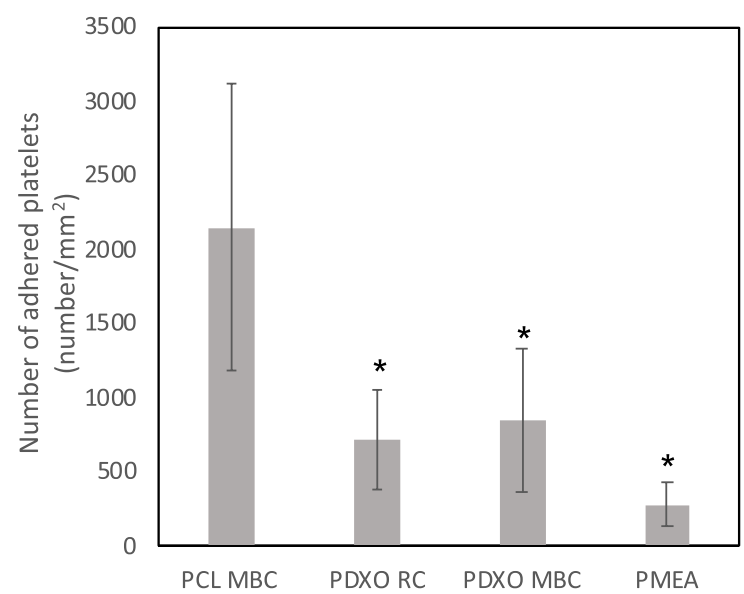

Figure 3. Platelet adhesion tests of PDXO copolymers ( $* P<0.01$ vs PCL MBC, $n=10)$. PCL MBC: PLGA-PCL MBC; PDXO MBC: PLGAPDXO MBC; PDXO RC: PLGA-PDXO RC.
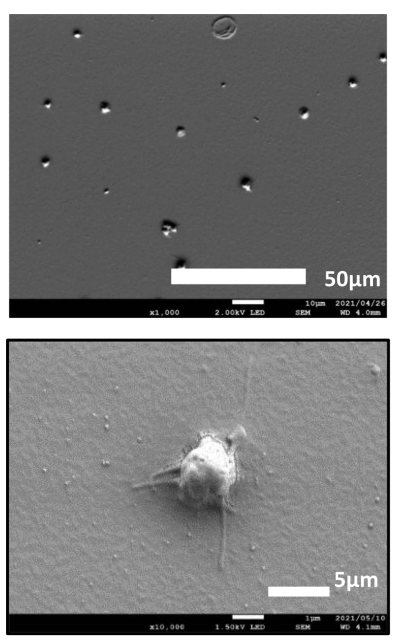

PLGA-PDXO MBC
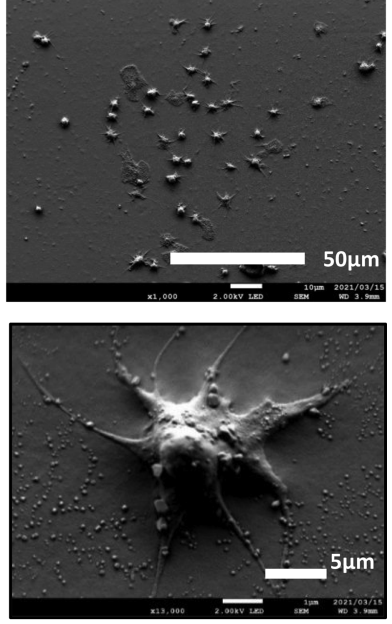

PLGA-PCL MBC

Figure 4. SEM images of an adhered platelet on the copolymer surface (PLGA-PDXO MBC: $M_{\mathrm{w}}=110,000, M_{\mathrm{w}} / M_{\mathrm{n}}=1.57$; PLGA-PCL MBC: $\left.M_{\mathrm{w}}=240,000, M_{\mathrm{w}} / M_{\mathrm{n}}=1.69\right)$.

in the copolymer may also affect platelet adhesion and is therefore currently being studied.

Fibrinogen Adsorption on the Polymer-Coated Surface. Platelet adhesion is known to occur after the adsorption of fibrinogen on the surface, while the orientation rather than the amount of fibrinogen adsorption has been shown to play a crucial role in platelet adhesion. ${ }^{39}$ Tanaka et al. reported that

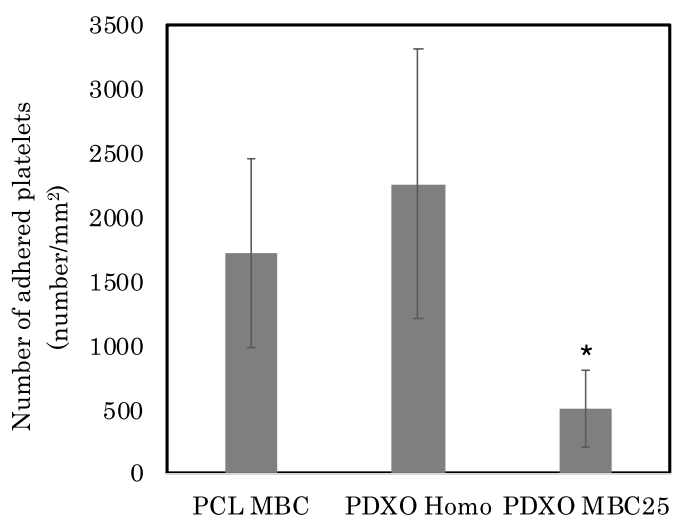

Figure 5. Platelet adhesion tests of the PDXO homopolymer $\left({ }^{*} P<\right.$ 0.01 vs PCL MBC, $n=25)$. PCL MBC: PLGA-PCL MBC; PDXO Homo: PDXO homopolymer; PDXO MBC25: PLGA-PDXO MBC.

fibrinogen is less adsorbed and less denatured on the PMEA surface compared to polypropylene. ${ }^{40}$ Fukushima et al. reported that the exposed peptide chain on the polycarbonate-bearing 2-methoxyethoxy carbonyl group may influence the platelet adhesion behavior, while the amount of the denatured fibrinogen $\gamma$-chain is low and comparable to PMEA. ${ }^{34}$ Rafailovich and co-workers reported that the exposed domain of adsorbed fibrinogen is highly dependent on the hydrophilicity and hydrophobicity of the polymer and its orientation affects the subsequent platelet and endothelial cell adhesion. ${ }^{41}$ 
(a) Anti-A $5529-539$

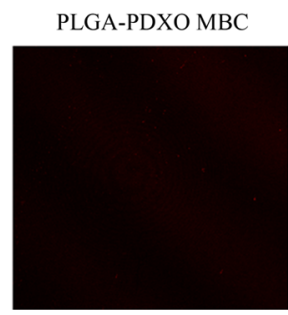

PLGA-PCL MBC

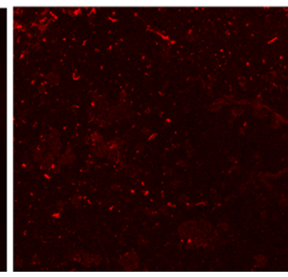

(b) Anti- $\gamma 86-41$

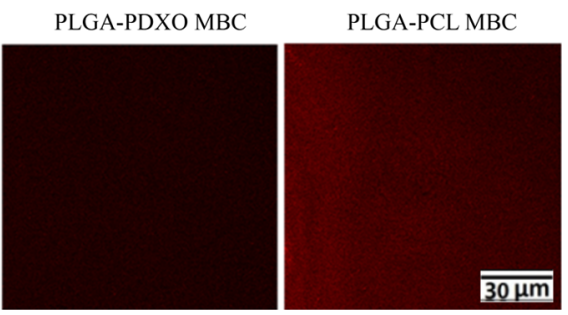

Figure 6. Confocal microscopic images of PLGA-PDXO MBC and PLGA-PCL MBC surfaces pre-incubated with $4 \mathrm{mg} / \mathrm{mL}$ fibrinogen. (a) AntiA $\alpha 529-539$ and (b) anti- $\gamma 86-411$.

Based on these findings, we compared the orientation of fibrinogen on the surface of PLGA-PDXO MBC and PLGAPCL MBC incubated with two monoclonal antifibrinogen IgG antibodies, anti-A $\alpha 529-539$ and anti- $\gamma 86-411$. The samples were imaged using red fluorescent anti-mouse secondary IgG [AffiniPure Goat Anti-Mouse IgG ( $\mathrm{H}+\mathrm{L})$ Dylight 649]. Clear red spots were observed on the surface of PLGA-PCL MBC incubated with anti-A $\alpha 529-539$ IgG (Figure 6), and the results of confocal microscopy were quantified by ELISA (Figure 7).

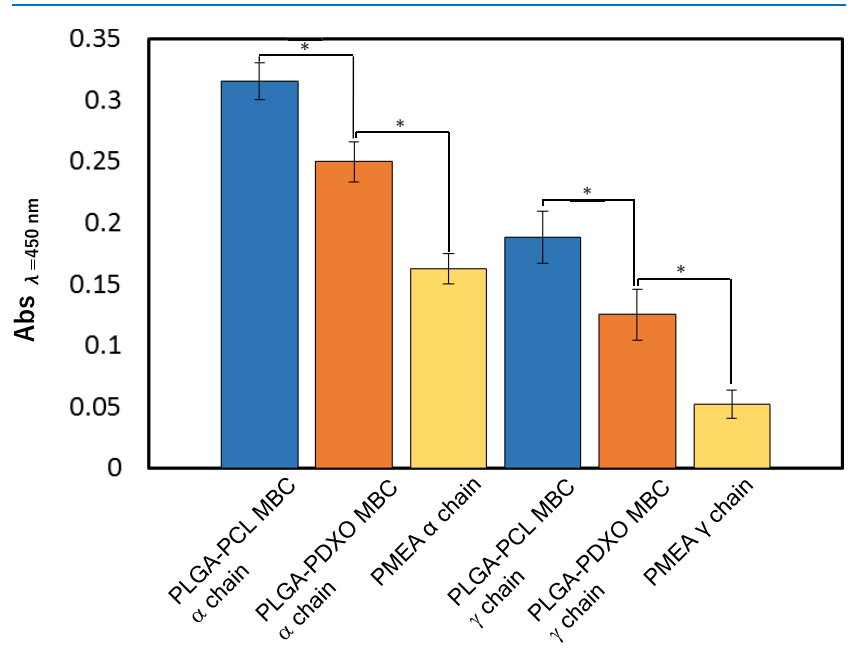

Figure 7. ELISA tests of fibrinogen monoclonal antibody against the $\alpha$ - or $\gamma$-chain $(n=8, * P<0.01)$.

PLGA-PCL MBC showed significantly higher absorbances $(P$ $<0.01$ ) compared to PLGA-PDXO MBC after incubation with both anti-A $\alpha 529-539$ IgG and anti- $\gamma 86-411$ IgG antibodies. This difference in the case of anti-A $\alpha 529-539$ IgG antibody was attributed to the higher hydrophobicity of PLGA-PCL MBC compared to PLGA-PDXO MBC, as the fibrinogen $\alpha \mathrm{C}$ regions are more exposed when fibrinogen is coated on a hydrophobic surface, thus contributing to fibrous fibrinogen aggregates, which in turn affect platelet adhesion. ${ }^{41} \mathrm{~A}$ significant difference was also observed in the absorbance of PLGA-PCL MBC compared to PLGA-PDXO MBC incubated with anti- $\gamma 86-411 \mathrm{IgG}$ antibody. Since the $\gamma$-chain contains receptor sites for platelets, the amount of the $\gamma$-chain on the copolymer surface would also affect the platelet adhesion behavior. The micro-bicinchoninic acid protein assay indicated that the amount of fibrinogen absorbed on the PLGA-PDXO MBC surface is comparable to that on PLGAPCL MBC (Figure S4). Therefore, we concluded that the different platelet adhesion behavior between the two copolymers resulted from the different orientations of fibrinogen on the surface. The orientation of fibrinogen on the copolymer surfaces was also compared to that on PMEA. PMEA showed significantly lower absorbances after incubation with both anti-A $\alpha 529-539$ IgG and anti- $\gamma 86-411$ IgG antibodies compared to those of PLGA-PDXO MBC and PLGAPCL MBC. The low level of the $\gamma$-chain exposed on the PMEA surface coated with fibrinogen was also reported in the literature. ${ }^{34}$ Therefore, the amount of $\alpha$ - and $\gamma$-chains of fibrinogen exposed on the polymer surface was PLGA-PCL MBC > PLGA-PDXO MBC > PMEA.

Other Physical Properties. MBCs comprising hard and soft segments show improved mechanical properties compared to their corresponding random copolymers. ${ }^{10,11}$ Free-standing films of PLGA-PDXO MBC were prepared by casting the polymer solution on glass plates. Based on the stress-strain curve of the PLGA-PDXO MBC film (Figure 8), its tensile

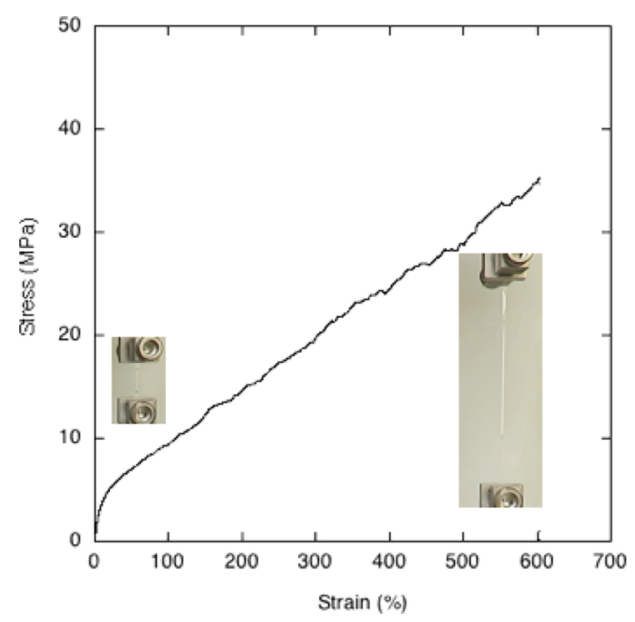

Figure 8. Stress-strain curve of the PLGA-PDXO MBC film. $M_{\mathrm{w}}=$ $152,000, M_{\mathrm{w}} / M_{\mathrm{n}}=1.67$. The degrees of polymerization of PDXO and L-lactide + glycolide segments are 24 and 29 , respectively.

strength and modulus were $34.3 \pm 1.63$ and $99.5 \pm 2.83 \mathrm{MPa}$ $(n=5)$, respectively. Moreover, the PLGA-PDXO MBC film was flexible and its elongation at break was over 500\%. These tensile properties were similar to those reported for PLGAPCL MBC and much better than the PLGA-PDXO random copolymer. ${ }^{11}$ The good tensile properties of PLGA-PDXO MBC were unique for an antiplatelet adhesive material and would favor the preparation of bioabsorbable implanting devices of the desired shape.

The PLGA-PDXO MBC film was also subjected to hydrolysis tests in PBS $(\mathrm{pH}=7.4)$ to further study for its biodegradation behavior. The average contact angle of the film surface $(n=2)$ decreased with increasing hydrolysis time 
(Figure 9), while the film (ca. $30 \mu \mathrm{m}$ ) became porous without losing its initial shape after hydrolysis for 14 weeks. A gradual

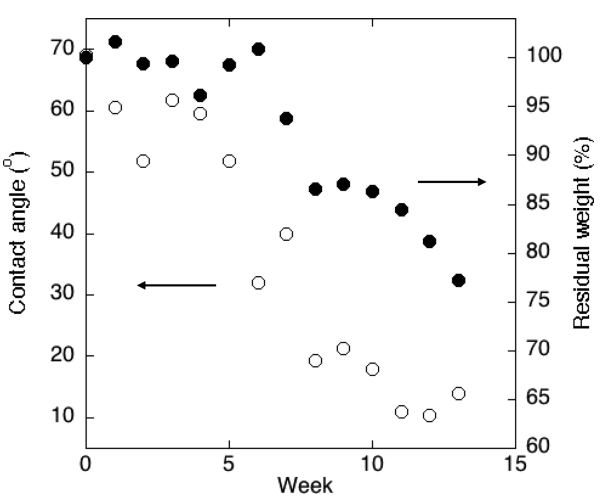

Figure 9. Hydrolysis of the PLGA-PDXO MBC film in PBS $(\mathrm{pH}=$ 7.4). $M_{\mathrm{w}}=129,000, M_{\mathrm{w}} / M_{\mathrm{n}}=2.03$. The degrees of polymerization of PDXO, L-lactide, and glycolide segments are 25, 24, and 3, respectively. Open plots represent the contact angle, and close plots represent the residual weight.

weight loss was also observed during the hydrolysis process (Figure 9). Hence, PLGA-PDXO MBC is hydrolyzable, but the hydrolysis rate is relatively low compared to bioabsorbable surgical sutures. ${ }^{42}$

\section{CONCLUSIONS}

In this study, we prepared copolymers consisting of PLGA and PDXO with good antiplatelet adhesion behavior compared to PLGA-PCL MBC due to the different orientations of fibrinogen on its surface. Compared to other antiplatelet adhesive materials, such as PMEA and PMPC, PLGA-PDXO MBC showed good tensile properties and biodegradation behavior, which can be exploited to develop new bioabsorbable implanting materials of implanting devices with specific shape suitable for application at blood-contacting sites. Further studies are currently being performed to examine the effect of the composition ratio and length of the PLGA and PDXO components, as well as the molecular weight of PLGA-PDXO MBC on its platelet adhesion, hydrolysis, and tensile properties.

\section{MATERIALS AND METHODS}

Polymers. For the synthesis of PLGA-PDXO MBC, 1,5dioxepan-2-one (DXO) (1.70 g, $14.6 \mathrm{mmol})$, diphenyl phosphate (DPP) (145 mg, $0.58 \mathrm{mmol})$, and benzyl alcohol $(60.8 \mu \mathrm{L}, 0.58 \mathrm{mmol})$ were charged into a heat-dried Schlenk flask under a nitrogen atmosphere. Dehydrated toluene $(6 \mathrm{~mL})$ was added, and the mixture was stirred at room temperature for $18 \mathrm{~h}$. Amberlyst A21 was subsequently added to the flask, and the flask was shaken using a shaker for an additional 30 min. After removing Amberlyst A21 by filtration, the filtrate was concentrated and dried at $60{ }^{\circ} \mathrm{C}$ in vacuo, affording the PDXO oligomer in $95 \%$ yield with a degree of polymerization of 26.4, as determined by ${ }^{1} \mathrm{H}$ NMR spectroscopy. Afterward, a solution of the PDXO oligomer (DP $=26.4,1.60 \mathrm{~g}, 0.523$ mmol) in dry tetrahydrofuran (THF; $6 \mathrm{~mL}$ ) was added to another heat-dried Schlenk flask comprising L-lactide $(1.76 \mathrm{~g}$, $12.2 \mathrm{mmol}$ ) and glycolide (158 $\mathrm{mg}, 1.36 \mathrm{mmol}$ ). After dissolving all contents upon stirring, 1,8-diazabicyclo[5.4.0]undec-7-ene (DBU) $(101 \mu \mathrm{L}, 0.68 \mathrm{mmol})$ was added to the flask to initiate the polymerization. After $1 \mathrm{~h}$ of stirring, benzoic acid $(0.17 \mathrm{~g}, 1.36 \mathrm{mmol})$ was added to terminate the reaction. The reaction mixture was poured into cold methanol, and the formed precipitate was collected by filtration and dried at $40{ }^{\circ} \mathrm{C}$ in vacuo, affording a benzyl-protected PLGA-PDXO diblock copolymer in $86 \%$ yield. The degrees of polymerization of PDXO, L-lactide, and glycolide were determined by ${ }^{1} \mathrm{H}$ NMR spectroscopy at 26.0, 23.4, and 2.5, respectively. The benzyl-protected PLGA-PDXO diblock copolymer (2.97 g) was then dissolved in THF $(120 \mathrm{~mL})$ in a round-bottom flask equipped with a three-way stopcock. After the addition of palladium on activated carbon $(0.30 \mathrm{~g})$, the flask was evacuated twice in vacuo and purged with nitrogen. After another evacuation and hydrogen purge, the mixture was stirred at room temperature for $15 \mathrm{~h}$. Then, hydrogen was evacuated, THF was evaporated, and chloroform $(180 \mathrm{~mL})$ was added to the mixture, which was stirred for another $3 \mathrm{~h}$. After filtration by Celite to remove palladium on activated carbon, the solution was concentrated and poured into cold methanol. The precipitate was recovered by filtration and dried at $40{ }^{\circ} \mathrm{C}$ in vacuo, affording the deprotected PLGA-PDXO diblock copolymer in $80 \%$ yield. The complete deprotection was confirmed by ${ }^{1} \mathrm{H}$ NMR measurement.

The deprotected PLGA-PDXO diblock copolymer (1.20 g), 4-(dimethylamino)pyridinium 4-toluenesulfonate (DPTS) (10.5 mg), and 4-(dimethylamino)pyridine (DMAP) (8.7 mg) were dissolved in dry dichloromethane $(4 \mathrm{~mL})$ in a heat-dried Schlenk flask under a nitrogen atmosphere. Molecular sieves (3 $\AA$ ) were then added, and the mixture was shaken for $15 \mathrm{~h}$. Then, $N, N^{\prime}$-diisopropylcarbodiimide (DIPCI) $(55.6 \mu \mathrm{L})$ was added to the solution, and the flask was shaken for another $3 \mathrm{~h}$. After removing the molecular sieves, the reaction mixture was poured into methanol and the formed precipitate was collected by filtration and dried at $40{ }^{\circ} \mathrm{C}$ in vacuo, affording PLGAPDXO MBC in $88 \%$ yield.

PLGA-PCL MBC was synthesized following the same process using $\varepsilon$-caprolactone instead of $\mathrm{DXO}$ to prepare the PCL oligomer. The PLLA-PDXO random copolymer (PLLA-PDXO RC) was synthesized by the bulk polymerization of L-lactide and DXO at $130{ }^{\circ} \mathrm{C}$ for $8 \mathrm{~h}$ in the presence of tin(II) 2-ethylhexanoate. The PDXO homopolymer was also synthesized by bulk polymerization of DXO at $100{ }^{\circ} \mathrm{C}$ for $12 \mathrm{~h}$ in the presence of tin 2-ethylhexanoate. PMEA was synthesized by the radical polymerization of 2-methoxyethylacrylate at 75 ${ }^{\circ} \mathrm{C}$ initiated by $2,2^{\prime}$-azobis(isobutyronitrile) in 1,4-dioxane. ${ }^{29}$

For the preparation of the polymer-coated surfaces, a solution of PLGA-PDXO MBC in chloroform $\left(20 \mathrm{mg} \mathrm{mL}^{-1}\right)$ was spin-coated onto a glass plate $(1000 \mathrm{rpm}, 15 \mathrm{~s})$. The coated glass plate was then dried under atmospheric pressure for $30 \mathrm{~min}$ and then in vacuo at $40{ }^{\circ} \mathrm{C}$ overnight.

Polymer-coated microplates were prepared using a polymer solution in chloroform $\left(20 \mathrm{mg} \mathrm{mL} \mathrm{mL}^{-1}, 20 \mu \mathrm{L}\right)$, which was poured into each well of a glass 96-well microplate. The microplate was dried under atmospheric pressure for $3 \mathrm{~h}$ and in vacuo at $40{ }^{\circ} \mathrm{C}$ overnight.

Free-standing films for tensile and hydrolysis tests were prepared by casting a chloroform solution of PLGA-PDXO $\mathrm{MBC}$ on a glass plate. The formed film was dried under atmospheric pressure at room temperature and in vacuo at 40 ${ }^{\circ} \mathrm{C}$ for $12 \mathrm{~h}$. The glass plate was immersed into water to remove the film, which was wiped and dried in vacuo at $40{ }^{\circ} \mathrm{C}$ for $12 \mathrm{~h}$. The film thickness was $30-60 \mu \mathrm{m}$.

Platelet Adhesion Tests. Platelet adhesion tests were performed based on our previous study. ${ }^{43}$ Briefly, citrated 
venous blood was collected from healthy volunteers using Quick Eye partner tubes. Platelet-rich plasma and platelet-poor plasma were obtained by centrifugation at $900 \mathrm{rpm}(150 \mathrm{~g})$ and $3000 \mathrm{rpm}(1670 \mathrm{~g})$, respectively, at $4{ }^{\circ} \mathrm{C}$ for $10 \mathrm{~min}$ using a Kubota 5910 refrigerated centrifuge (Tokyo, Japan). The platelet concentration was determined by an automated hematology analyzer (Sysmex XE-5000, Sysmex, Kobe, Japan) and adjusted to approximately $5 \times 10^{7}$ cells $\mathrm{mL}^{-1}$. Informed consent was obtained from all subjects, in accordance with the Declaration of Helsinki, and the study protocol was approved by the Ethics Committee of Akita University.

Each platelet suspension $(200 \mu \mathrm{L})$ was placed on the polymer surface of a glass plate and incubated at $37^{\circ} \mathrm{C}$ for $1 \mathrm{~h}$. After washing the plate with PBS $(\mathrm{pH}=7.4)$, the adhered platelets were fixed by immersing the plate into $1 \%$ glutaraldehyde in PBS at $37{ }^{\circ} \mathrm{C}$ for $30 \mathrm{~min}$. The film was further washed with PBS and incubated with Perm/Wash buffer $(0.4 \mathrm{~mL})$ diluted with PBS $(3.6 \mathrm{~mL})$ at room temperature for $10 \mathrm{~min}$. Afterward, the film was stained with ActinGreen 488 Ready Probes reagent for 30 min in the dark according to the manufacturer's instructions. After washing with PBS, the film was observed using a fluorescence microscope, and quantitative analysis was performed by counting the green spots on the films (stained platelets). Two independent films were examined, and five different areas were counted on each film. The average number of adhered platelets was estimated based on 10 images.

Fibrinogen Adsorption on the Polymer-Coated Surface. For the confocal microscopic measurements, a solution of fibrinogen $\left(4 \mathrm{mg} \mathrm{mL}^{-1}, 100 \mu \mathrm{L}\right)$ in tris-buffered saline (TBS, $\mathrm{pH}=7.4$ ) was first placed on the polymer-coated plate surface and incubated at room temperature overnight. After washing the surface with TBS three times, a monoclonal antifibrinogen IgG antibody (anti-A $\alpha 529-539$ or anti- $\gamma 86-411$, ca. $1 \mu \mathrm{g} \mathrm{mL}^{-1}, 100 \mu \mathrm{L}$ ) was placed on the surface and the plate was left at $4{ }^{\circ} \mathrm{C}$ overnight. After washing the surface with TBS three times, AffiniPure Goat Anti-Mouse IgG $(\mathrm{H}+\mathrm{L})$ Dylight $649\left(1 \mu \mathrm{g} \mathrm{mL}^{-1}, 100 \mu \mathrm{L}\right)$ was placed on the surface and the plate was left at room temperature in the dark place for $1.5 \mathrm{~h}$. After washing again with TBS three times, the plate surface was observed using a confocal laser microscope (LSM780, Carl Zeiss Co., Ltd., Tokyo, Japan).

For the enzyme-linked immune sorbent assay (ELISA), a solution of fibrinogen $\left(4 \mathrm{mg} \mathrm{mL}^{-1}, 50 \mu \mathrm{L}\right)$ in TBS was poured into each well of the polymer-coated microplate, followed by incubation at room temperature overnight. After washing the well with TBS three times, a monoclonal antifibrinogen IgG antibody (anti-A $\alpha 529-539$ or anti- $\gamma 86-411$, ca. $1 \mu \mathrm{g} \mathrm{mL} \mathrm{L}^{-1}, 50$ $\mu \mathrm{L}$ ) was added and the microplate was left at $4{ }^{\circ} \mathrm{C}$ overnight. After washing the well with TBS three times, Goat Anti-Mouse $\mathrm{IgG}_{1}$-HRP $\left(1 \mu \mathrm{g} \mathrm{mL}^{-1}, 50 \mu \mathrm{L}\right)$ was added and the microplate was left at room temperature for $30 \mathrm{~min}$. After washing again with TBS three times, ABTS Microwell Peroxidase Substrate $\left(1 \mu \mathrm{g} \mathrm{mL}^{-1}, 100 \mu \mathrm{L}\right)$ was poured into the well and the microplate was left at room temperature for $30 \mathrm{~min}$. The supernatant solution $(90 \mu \mathrm{L})$ was finally transferred to an empty well, and the absorption at $450 \mathrm{~nm}$ was measured using a microplate reader.

Statistical Analysis. Statistical analysis was performed using two-sided Student $t$-test and Microsoft Excel.

\section{ASSOCIATED CONTENT}

\section{(s) Supporting Information}

The Supporting Information is available free of charge at https://pubs.acs.org/doi/10.1021/acsomega.1c03846.

Experimental details such as materials, characterization, hydrolysis test, micro-bicinchoninic acid (BCA) protein assay, ${ }^{1} \mathrm{H}$ NMR spectra of the PDXO oligomer and PLGA-PDXO diblock copolymer, AFM images of PLGA-PDXO MBC and PLGA-PDXO RC, and micro-BCA tests of fibrinogen (PDF)

\section{AUTHOR INFORMATION}

\section{Corresponding Author}

Mitsutoshi Jikei - Department of Materials Engineering, Graduate School of Engineering Science, Akita University, Akita 010-8502, Japan; @ orcid.org/0000-0002-84648677; Email: mjikei@gipc.akita-u.ac.jp

\section{Authors}

Mao Takeda - Department of Materials Engineering, Graduate School of Engineering Science, Akita University, Akita 010-8502, Japan

Yoshiki Kaneda - Department of Materials Engineering, Graduate School of Engineering Science, Akita University, Akita 010-8502, Japan

Kohei Kudo - Department of Materials Engineering, Graduate School of Engineering Science, Akita University, Akita 010-8502, Japan

Nozomi Tanaka - Department of Materials Engineering, Graduate School of Engineering Science, Akita University, Akita 010-8502, Japan

Kazuya Matsumoto - Department of Materials Engineering, Graduate School of Engineering Science, Akita University, Akita 010-8502, Japan; @ orcid.org/0000-0001-90360365

Masaki Hikida - Department of Life Science, Graduate School of Engineering Science, Akita University, Akita 010-8502, Japan

Shigeharu Ueki - Department of General Internal Medicine and Clinical Laboratory Medicine, Graduate School of Medicine, Akita University, Akita 010-8543, Japan; ๑ orcid.org/0000-0002-3537-7735

Complete contact information is available at:

https://pubs.acs.org/10.1021/acsomega.1c03846

\section{Notes}

The authors declare no competing financial interest.

\section{ACKNOWLEDGMENTS}

The authors acknowledge the kind gift of monoclonal antifibrinogen IgG antibodies by D. K. Galanakis in Stony Brook University Hospital, NY. This work is partially supported by Japan Agency for Medical Research and Development under grant numbers JP181m0203002 and JP19lm0203002.

\section{REFERENCES}

(1) Ikada, Y.; Tsuji, H. Biodegradable polyesters for medical and ecological applications. Macromol. Rapid Commun. 2000, 21, 117132.

(2) Gunatillake, P. A.; Adhikari, R. Biodegradable Synthetic Polymers For Tissue Engineering. Eur. Cells Mater. 2003, 5, 1-16. 
(3) Dorgan, J. R.; Braun, B.; Wegner, J. R.; Knauss, D. M. Poly(lactic acids): A Brief Review. ACS Symp. Ser. 2006, 939, 102-125.

(4) Nampoothiri, K. M.; Nair, N. R.; John, R. P. An overview of the recent developments in polylactide (PLA) research. Bioresour. Technol. 2010, 101, 8493-8501.

(5) Ulery, B. D.; Nair, L. S.; Laurencin, C. T. Biomedical Applications of Biodegradable Polymers. J. Polym. Sci., Part B: Polym. Phys. 2011, 49, 832-864.

(6) Tian, H.; Tang, Z.; Zhuang, X.; Chen, X.; Jing, X. Biodegradable synthetic polymers: Preparation, functionalization and biomedical application. Prog. Polym. Sci. 2012, 37, 237-280.

(7) Nair, L. S.; Laurencin, C. T. Biodegradable polymers as biomaterials. Prog. Polym. Sci. 2007, 32, 762-798.

(8) Shi, R.; Chen, D.; Liu, Q.; Wu, Y.; Xu, X.; Zhang, L.; Tian, W. Recent advances in synthetic bioelastomers. Int. J. Mol. Sci. 2009, 10, $4223-4256$

(9) Li, Y.; Thouas, G. A.; Chen, Q.-Z. Biodegradable soft elastomers: synthesis/properties of materials and fabrication of scaffolds. RSC Adv. 2012, 2, 8229-8242.

(10) Jikei, M.; Takeyama, Y.; Yamadoi, Y.; Shinbo, N.; Matsumoto, K.; Motokawa, M.; Ishibashi, K.; Yamamoto, F. Synthesis and properties of poly(L-lactide)-poly( $\varepsilon$-caprolactone) multiblock copolymers by the self-polycondensation of diblock macromonomers. Polym. J. 2015, 47, 657-665.

(11) Jikei, M.; Suga, T.; Yamadoi, Y.; Matsumoto, K. Synthesis and properties of poly(L-lactide-co-glycolide)- $b$-poly $(\varepsilon$-caprolactone $)$ multiblock copolymers formed by self-polycondensation of diblock macromonomers. Polym. J. 2017, 49, 369-375.

(12) Jikei, M.; Yamadoi, Y.; Suga, T.; Matsumoto, K. Stereocomplex formation of poly(L-lactide)-poly( $\varepsilon$-caprolactone $)$ multiblock copolymers with poly(D-lactide). Polymer 2017, 123, 73-80.

(13) Suga, T.; Xuyen, N.-T.; Matsumoto, K.; Jikei, M.; Takahashi, K.; Kubota, H.; Tamura, T. Enhanced proliferation of HeLa cells on PLLA-PCL and PLGA-PCL multiblock copolymers. Polym. J. 2017, 49, 567-573.

(14) Okano, T.; Nishiyama, S.; Shinohara, I.; Akaike, T.; Sakurai, Y.; Kataoka, K.; Tsuruta, T. Effect of hydrophilic and hydrophobic microdomains on mode of interaction between block polymer and blood platelets. J. Biomed. Mater. Res. 1981, 15, 393-402.

(15) Okano, T.; Aoyagi, T.; Kataoka, K.; Abe, K.; Sakurai, Y.; Shimada, M.; Shinohara, I. Hydrophilic-hydrophobic microdomain surfaces having an ability to suppress platelet aggregation and their in vitro antithrombogenicity. J. Biomed. Mater. Res. 1986, 20, 919-927.

(16) Okano, T.; Uruno, M.; Sugiyama, N.; Shimada, M.; Shinohara, I.; Kataoka, K.; Sakurai, Y. Suppression of platelet activity on microdomain surfaces of 2-hydroxyethyl methacrylate-polyether block copolymers. J. Biomed. Mater. Res. 1986, 20, 1035-1047.

(17) Yui, N.; Tanaka, J.; Sanui, K.; Ogata, N.; Kataoka, K.; Okano, T.; Sakurai, Y. Characterization of the microstructure of poly(propylene oxide)-segmented polyamide and its suppression of platelet adhesion. Polym. J. 1984, 16, 119-128.

(18) Yui, N.; Sanui, K.; Ogata, N.; Kataoka, K.; Okano, T.; Sakurai, Y. Effect of microstructure of poly(propylene-oxide)-segmented polyamides on platelet adhesion. J. Biomed. Mater. Res. 1986, 20, 929-943.

(19) Nojima, K.; Sanui, K.; Ogata, N.; Yui, N.; Kataoka, K.; Sakurai, Y. Material characterization of segmented polyether poly(urethaneurea-amide)s and its implication in blood compatibility. Polymer 1987, 28, 1017-1024.

(20) Takei, Y. G.; Yui, N.; Okano, T.; Maruyama, A.; Sanui, K.; Sakurai, Y.; Ogata, N. Postadsorptive behavior of plasma proteins on poly(propylene oxide)-segmented nylon-610 surfaces and its implication in preventing contact-induced activation of platelets on these surfaces. J Biomater. Sci. Polym. Ed. 1995, 6, 149-168.

(21) Kawamoto, N.; Mori, H.; Terano, M.; Yui, N. Blood compatibility of polypropylene surfaces in relation to the crystallineamorphous microstructure. J. Biomater. Sci., Polym. Ed. 1997, 8, 859877.
(22) Ishihara, K.; Aragaki, R.; Ueda, T.; Watanabe, A.; Nakabayashi, $\mathrm{N}$. Reduced thrombogenicity of polymers having phospholipid polar groups. J. Biomed. Mater. Res. 1990, 24, 1069-1077.

(23) Ishihara, K.; Ziats, N. P.; Tierney, B. P.; Nakabayashi, N.; Anderson, J. M. Protein adsorption from human plasma is reduced on phospholipid polymers. J. Biomed. Mater. Res. 1991, 25, 1397-1407.

(24) Ishihara, K.; Oshida, H.; Endo, Y.; Ueda, T.; Watanabe, A.; Nakabayashi, N. Hemocompatibility of human whole blood on polymers with a phospholipid polar group and its mechanism. J. Biomed. Mater. Res. 1992, 26, 1543-1552.

(25) Ueda, T.; Oshida, H.; Kurita, K.; Ishihara, K.; Nakabayashi, N. Preparation of 2-methacryloyloxyethyl phosphorylcholine copolymers with alkyl methacrylates and their blood compatibility. Polym. J. 1992, $24,1259-1269$

(26) Ishihara, K. Revolutionary advances in 2-methacryloyloxyethyl phosphorylcholine polymers as biomaterials. J. Biomed. Mater. Res. A 2019, 107, 933-943.

(27) Ishihara, K. Highly lubricated polymer interfaces for advanced artificial hip joints through biomimetic design. Polym. J. 2015, 47, 585-597.

(28) Tanaka, M.; Motomura, T.; Kawada, M.; Anzai, T.; Kasori, Y.; Shiroya, T.; Shimura, K.; Onishi, M.; Mochizuki, A. Blood compatible aspects of poly(2-methoxyethylacrylate) (PMEA)-relationship between protein adsorption and platelet adhesion on PMEA surface. Biomaterials 2000, 21, 1471-1481.

(29) Tanaka, M.; Mochizuki, A.; Ishii, N.; Motomura, T.; Hatakeyama, T. Study of Blood compatibility with poly(2methoxyethyl acrylate). Relationship between water structure and platelet compatibility in poly(2-methoxyethylacrylate-co-2-hydroxyethylmethacrylate). Biomacromolecules 2002, 3, 36-41.

(30) Tanaka, M.; Sato, K.; Kitakami, E.; Kobayashi, S.; Hoshiba, T.; Fukushima, K. Design of biocompatible and biodegradable polymers based on intermediate water concept. Polym. J. 2015, 47, 114-121.

(31) Hoshiba, T.; Nemoto, E.; Sato, K.; Orui, T.; Otaki, T.; Yoshihiro, A.; Tanaka, M. Regulation of the contribution of integrin to cell attachment on poly(2-methoxyethyl acrylate) (PMEA) analogous polymers for attachment-based cell enrichment. PLoS One 2015, 10, No. e0136066.

(32) Hoshiba, T.; Nemoto, E.; Sato, K.; Maruyama, H.; Endo, C.; Tanaka, M. Promotion of adipogenesis of 3T3-L1 cells on protein adsorption-suppressing poly(2-methoxyethyl acrylate) analogs. Biomacromolecules 2016, 17, 3808-3815.

(33) HOSHIBA, T.; TANAKA, M. Integrin-independent cell adhesion substrates: Possibility of applications for mechanobiology research. Anal. Sci. 2016, 32, 1151-1158.

(34) Fukushima, K.; Inoue, Y.; Haga, Y.; Ota, T.; Honda, K.; Sato, C.; Tanaka, M. Monoether-tagged biodegradable polycarbonate preventing platelet adhesion and demonstrating vascular cell adhesion: A promising material for resorbable vascular grafts and stents. Biomacromolecules 2017, 18, 3834-3843.

(35) Mathisen, T.; Albertsson, A.-C. Polymerization of 1,5-dioxepan2-one. 1. Synthesis and characterization of the monomer 1,5dioxepan-2-one and its cyclic dimer 1,5,8,12-tetraoxacyclotetradecane-2,9-dione. Macromolecules 1989, 22, 3838-3842.

(36) Mathisen, T.; Masus, K.; Albertsson, A.-C. Polymerization of 1,5-dioxepan-2-one. 2. Polymerization of 1,5-dioxepan-2-one and its cyclic dimer, including a new procedure for the synthesis of 1,5dioxepan-2-one. Macromolecules 1989, 22, 3842-3846.

(37) Albertsson, A.-C.; Palmgren, R. Polymerization and degradation of 1,5-dioxepan-2-one. J. Macromol. Sci., Part A: Pure Appl. Chem. 1993, 30, 919-931.

(38) Ryner, M.; Albertsson, A.-C. Resorbable and highly elastic block copolymers from 1,5-dioxepan-2-one and L-lactide with controlled tensile properties and hydrophilicity. Biomacromolecules 2002, 3, 601-608.

(39) Sivaraman, B.; Latour, R. A. The relationship between platelet adhesion on surfaces and the structure versus the amount of adsorbed fibrinogen. Biomaterials 2010, 31, 832-839. 
(40) Tanaka, M.; Mochizuki, A.; Shiroya, T.; Motomura, T.; Shimura, K.; Onishi, M.; Okahata, Y. Study on kinetics of early stage protein adsorption on poly (2-methoxyethylacrylate) (PMEA) surface. Colloids Surf., A 2002, 203, 195-204.

(41) Zhang, L.; Casey, B.; Galanakis, D. K.; Marmorat, C.; Skoog, S.; Vorvolakos, K.; Simon, M.; Rafailovich, M. H. The influence of surface chemistry on adsorbed fibrinogen conformation, orientation, fiber formation and platelet adhesion. Acta Biomater. 2017, 54, 164174.

(42) Amass, W.; Amass, A.; Tighe, B. A review of biodegradable polymers: Uses, current developments in the synthesis and characterization of biodegradable polyesters, blends of biodegrdable polymers and recent advances in biodegradation studies. Polym. Int. 1998, 47, 89-144.

(43) Jikei, M.; Kobayashi, Y.; Matsumoto, K.; Hirokawa, M.; Ueki, S. Antiplatelet adhesion behavior of hyperbranched poly(L-lactide)s containing glutamic acid terminal groups. J. Appl. Polym. Sci. 2019, 136, 46910. (7page) 